\title{
UMA ABORDAGEM HISTÓRICA DE PRÁTICAS E REPRESENTAÇÕES DA ASSISTÊNCIA E DA EDUCAÇÃO VOLTADAS À PRIMEIRA INFÂNCIA EM FRANCISCO BELTRÃO/PR (1950 - 1980)
}

A HISTORICAL APPROACH OF THE PRACTICES AND REPRESENTATIONS OF ASSISTANCE AND EDUCATION TO EARLY CHILDHOOD IN FRANCISCO BELTRÃO-PR (1950 - 1980)

\author{
Caroline Machado Cortelini Conceição* \\ cmcortelini@yahoo.com.br
}

RESUMO: Este texto tem como proposta visibilizar processos de constituição da infância na sociedade. Realiza uma abordagem histórica do atendimento à primeira infância em Francisco Beltrão/PR, assinalando diferentes práticas. Tem como base teórica e metodológica a História Cultural. Documentos escritos e orais compõem o material de análise da pesquisa. Tem destaque o papel desempenhado pela Associação de Proteção à Maternidade e a Infância desde o início da organização política do município. A pesquisa permite perceber o lugar ocupado pela infância na sociedade ao visibilizar práticas e representações que dizem respeito à criança, à assistência social e à educação.

PALAVRAS-CHAVE: História da Infância, Assistência, Educação Infantil.

ABSTRACT: This text is as visualize childhood Constitution processes in society. Performs a historical approach of early childhood care in Francisco Beltrão-PR, highlighting different practices. Is based on methodological and theoretical Cultural history. Written and oral documents make up the analysis of the research material. Has highlighted the role played by the Association of protection of motherhood and Childhood since the beginning of the political organization of the municipality. The survey allows to perceive the place occupied by the children in society to make practices and representations concerning the child, social assistance and education.

KEYWORDS: History of Childhood, Assistance, Early Childhood Education.

\section{Introdução}

Este texto apresenta dados de pesquisa que tem como proposta visibilizar processos de constituição da infância na sociedade, a partir da compreensão de que uma abordagem historiográfica sobre a infância permite identificar os contornos de "condições específicas de existência para as crianças, em cada espaço-tempo" (SARMENTO, 2011, p. 584). Considerando que o trabalho da história "é sempre o de dar a ver um outro", a investigação propõe tornar visível infâncias que se fizeram presentes no contexto investigado (PESAVENTO, 2008, p. 59).

Estudos de Ariès (1981), Heywood (2004), Del Priore (2006), dentre outros, possibilitam a compreensão de que a infância é construção histórica e os modos de ser criança e viver a infância são variáveis, de acordo com as práticas sociais estabelecidas em

\footnotetext{
*Doutora em Educação pela Universidade do Vale do Rio dos Sinos. Mestre em Educação pela Universidade Federal de Santa Maria. Professora Adjunta da Universidade Estadual do Oeste do Paraná - Campus de Francisco Beltrão - Centro de Ciências Humanas.
} 
diferentes espaços e tempos, sobressaindo-se a necessidade de pesquisas que permitam dar visibilidade às diferentes infâncias, com a finalidade de ampliar a apreensão de suas singularidades. O atual movimento investigativo sobre a infância tem possibilitado a percepção de uma diversidade de processos históricos, os quais evidenciam uma pluralidade de infâncias, definidas pelas múltiplas vivências dos sujeitos a partir de seu pertencimento social, étnico-racial, religioso, de gênero, dentre outros (ROCHA E GOUVÊA, 2010). Nesse sentido:

Mais que o enriquecimento do olhar sobre o tema, tal transformação tem significado uma mudança epistemológica, em que a infância é entendida como categoria social, que informa a inserção de sujeitos concretos, ou seja, uma categoria que permite interrogar sobre a inserção de crianças na vida social, em diferentes tempos históricos e espaços sociais. [...] Assim é que esses estudos vêm produzindo novos aportes teóricos e estratégias investigativas, no esforço de contemplar a singularidade de tal sujeito em sua ação no mundo. (ROCHA E GOUVÊA, 2010, p. 190)

Tais estudos propõem novas perspectivas de análise sobre a infância e compõem o campo dos estudos da criança que enfrenta o desafio de consolidar-se, na atualidade, como um campo interdisciplinar influente na produção do conhecimento sobre as crianças. Nesse sentido, é importante considerar que há uma complexidade de fatores intervenientes na história da infância e da educação infantil, o que implica em compreendê-las como parte integrante da produção da história, em que a história das outras instituições educacionais, da família, da população, da urbanização, do trabalho e das relações de produção estão em estreita relação (KUHLMANN JR, 2004).

Com o intuito de possibilitar o conhecimento sobre a infância em um espaço-tempo específico, este trabalho tem na História Cultural (PESAVENTO, 2008; BURKE, 2008) as bases teórica e metodológica. A partir dessa perspectiva, documentos escritos e as memórias de diversos sujeitos envolvidos no processo ${ }^{1}$ são tomados como documentos e servem para refletir e compreender o passado. Assim, a presente escrita realiza uma abordagem histórica do atendimento à primeira infância em Francisco Beltrão/PR, assinalando diferentes práticas de assistência e educação da criança no município.

\footnotetext{
${ }^{1}$ Foram realizadas entrevistas com profissionais que atuaram na gestão municipal e nas creches durante a década de 1980, período em que foram criadas as primeiras instituições públicas de atendimento à infância no contexto investigado.
} 
As memórias, conforme Stephanou e Bastos (2005), constituem-se em indícios que possibilitam ao historiador produzir leituras do passado. Por isso, faz-se a opção pela metodologia da História Oral que, ao utilizar-se da memória, permite aprofundar a compreensão sobre aspectos do contexto no qual se desenvolve a pesquisa, principalmente os culturais e estruturais de uma sociedade, de tal modo que "a memória constitui-se em documento, e a história oral é a metodologia aplicada no intuito de operacionalizar o diálogo entre teoria e dados empíricos, promovendo outras perspectivas de conhecimento do passado" (GRAZZIOTIN; ALMEIDA, 2012, p. 35-36).

Nesse sentido, diferentes documentos são articulados na pesquisa, para a compreensão do contexto, com a finalidade de identificar as condições que fizeram emergir personagens, itinerários e acontecimentos no período delimitado (FISCHER, 2008). De acordo com Pesavento (2008), sob o ponto de vista da história cultural, o pesquisador acessa o tempo passado através de registros e sinais do passado, que são representações do acontecido e que, através de seu olhar, constituem-se em documentos para a pesquisa.

Nessa perspectiva, nos detemos a olhar as práticas e representações considerando que "não existe prática que não se articule sobre as representações pelas quais os indivíduos constroem o sentido de tal existência - um sentido inscrito nas palavras, nos gestos, nos ritos", todas as práticas sociais, sejam elas econômicas, políticas, etc., "todas são ao mesmo tempo "culturais", já que traduzem em atos as maneiras plurais como os homens dão significação ao mundo que é seu" (CHARTIER, 2002, p. 18). É sob esta perspectiva, a da cultura, que a história cultural nos auxilia olhar as múltiplas dimensões da vida humana.

É importante analisar a cultura beltronense nas tensões entre uma memória oficial que apregoa as vitórias de alguns pelo bem comum, os heróis pioneiros, e as memórias subterrâneas, na acepção proposta por Pollak (1989), que num primeiro olhar não estão tão evidentes. Contudo, os silêncios sobre as matizes dos acontecimentos, como nos indica Pollak (1989), ao invés de conduzir ao esquecimento, significam a resistência de um determinado grupo que se vê impotente aos discursos oficiais. Ele assinala que estas memórias permanecem sendo transmitidas entre redes de familiares e amigos. Assim, as memórias do lugar se estabelecem num contexto de tensões, conflitos e disputas. A memória é representação e, nesse sentido, é preciso entender as representações como 
"matrizes geradoras de condutas e práticas sociais" que qualificam o mundo e ao mesmo tempo orientam o olhar e a percepção sobre essa realidade (PESAVENTO, 2008).

A história oficial está pautada pelo discurso dos pioneiros. Contudo, tal discurso impõe uma hegemonia cultural e oculta "relações de poder, de imposições e subordinações expressas no contexto da complexa divisão do trabalho, das lutas de classes, das relações de posses sujeitas a pessoas/famílias/grupos que detêm a hegemonia econômica" (FLAVIO, 2011, p. 92). Com isso, se omite a presença e as marcas dos grupos indígenas e caboclos, no sudoeste paranaense, que já viviam na região antes da chegada dos chamados pioneiros e que foram "asfixiados territorialmente" ou desalojados de suas terras. Oculta-se a mestiçagem da população, enfatizando-se somente sua matriz eurodescendente, quando é preciso salientar a presença das diversas etnias que compõem a população sudoestina e beltronense (FLAVIO, 2011).

Francisco Beltrão/PR é um município relativamente jovem, com 66 anos de existência. Sua origem está vinculada a processo que contempla uma "dinâmica de reterritorialização [...], de descendentes de imigrantes italianos, alemães e poloneses a partir das décadas de 1940 e 1950", provenientes em grande parte dos estados do Rio Grande do Sul e Santa Catarina, motivado pelas políticas de "redefinições de fronteiras pelas quais passaram o Brasil e o estado do Paraná face à expansão urbano-industrial, principalmente no período após os anos 1930 a 1940, na "Era Vargas"” (FLÁVIO, 2011, p. 64). Foi a chamada "marcha para o Oeste" que visava ocupar as fronteiras consideradas "abandonadas", "desocupadas", "devolutas" (LAZIER, 1997).

A criação da Colônia Agrícola Nacional General Osório - $\mathrm{CANGO}^{2}$ efetuou papel decisivo no contexto local: "realizou eficiente trabalho de povoamento e colonização, construindo obras de infraestrutura, dinamizando a vida social e cultural da comunidade" 3 (LAZIER, 1997, p. 41). Conforme Flávio (2011), dirigiu o processo de ocupação do território. Nessa perspectiva, Francisco Beltrão se constituiu como um polo importante das relações

\footnotetext{
${ }^{2}$ Criada a partir do decreto 12.417 de 12 de maio de 1943, na faixa de $60 \mathrm{~km}$ da fronteira desde a região de Barracão-Santo Antônio, a ser demarcada pela Divisão de Terras e colonização do Departamento Nacional de Produção Vegetal do Ministério da Agricultura, com a finalidade de ocupar a região de fronteiras em questão. Foi extinta em 1954, passando a Núcleo Colonial do Instituto Nacional de Imigração e Colonização - INIC (FLÁVIO, 2011).

${ }^{3}$ Lazier (1997) indica que, em 3 anos (1947 a 1950), a população da colônia aumentou 288,85\%.
} 
urbano-rurais estabelecidas, no âmbito do sudoeste paranaense, "localidade central na ocupação do sudoeste paranaense", configurando-se como centro econômico, político e cultural no processo de ocupação efetuado pelos migrantes (FLÁVIO, 2011, 78). Ainda é importante sinalizar que a Revolta dos Posseiros, que culminou em 1957, também desempenhou importante papel no município.

Em palavras muito breves é importante anunciar este evento que envolveu disputas pelo controle do território e seus recursos, envolvendo o segmento rural e urbano (FLÁVIO, 2011). A região do sudoeste do Paraná era ocupada por posseiros (aquele que pretende a posse legítima de terras que desbravou ou está de posse de terras devolutas - alguns eram posseiros oficiais pois haviam recebido da Cango um protocolo), pois a propriedade da terra na região estava sendo questionada pela justiça. A partir de 1950 a empresa Clevelêndia Industrial Territorial Ltda (CITLA) recebeu do governo estadual o direito pelas terras em negociação de pagamento de indenização. A esse respeito, Lazier (1997) pontua que a Revolta configurou-se em uma negociação política "ilegal e imoral". A CITLA e outras companhias imobiliárias passaram a requerer o direito de propriedade aos posseiros, obrigando-os ao pagamento das terras, fazendo uso de jagunços. O evento culmina com um levante dos posseiros, em 1957, que expulsam as companhias e os jagunços da cidade. A "conquista de Francisco Beltrão" é considerada o ápice do movimento, pois aí se encontravam os escritórios das principais companhias imobiliárias. Os posseiros reivindicam ao Estado o título de propriedade privada da terra. Após esses acontecimentos, o Grupo Executivo para as Terras do Sudoeste do Paraná (Getsop) expediu inúmeros títulos de propriedade de lotes urbanos e rurais na região (FLÁVIO, 2011, LAZIER, 1997).

O texto que segue tem como objetivo constituir, a partir de memórias e outros documentos, aspectos das práticas cotidianas no campo da assistência e educação voltados à primeira infância no município de Francisco Beltrão/PR, no período compreendido entre 1950 e 1980. Efetua uma abordagem sobre as ações desenvolvidas pela Associação de Proteção à Maternidade e a Infância, entidade que desempenhou um papel central na assistência à infância desde o início da organização política do município. Também acentua outras práticas identificadas no contexto investigado, como a de cuidadora doméstica. E no campo da educação, as ações do MOBRAL e a criação das primeiras creches são aqui enfocadas. 


\section{A assistência à infância: as ações da associação de proteção à maternidade e a infância}

O histórico do atendimento à infância em Francisco Beltrão é marcado pela criação da Associação de Proteção à Maternidade e à Infância Dr. Haroldo Beltrão - APMI. As APMIs foram disseminadas, no Brasil, na segunda metade do século XX, contando com o apoio técnico e financeiro da Legião Brasileira de Assistência, com ações voltadas à proteção da criança e da mãe. A APMI Dr. Haroldo Beltrão foi criada no mesmo ano de independência política do município, em 1952, pelo médico Rubens da Silva Martins ${ }^{4}$, juntamente com senhoras da comunidade. $\mathrm{O}$ autor explicita sua motivação:

Movido pelo desejo de prestar às crianças desamparadas e às gestantes de baixa renda, carentes de recursos de toda ordem, uma ampla cobertura assistencial, fundei, em três de março de 1952, com a participação dos membros da comunidade marrecoana a Associação de Proteção à Maternidade e à Infância "Dr. Haroldo Beltrão", conforme ata registrada no Cartório de Títulos e Documentos do 10. Ofício, em Curitiba (MARTINS, 1986, p.113).

A entidade captou recursos junto ao Departamento Estadual da Criança ${ }^{5}$ para a construção de um Posto de Puericultura ${ }^{6}$. O autor sinaliza qual era seu projeto para o posto, o qual tinha como finalidade atender às mães pobres da comunidade:

Antes do início das obras, eu me empenhei para que em seu lugar fosse construído um grande pavilhão de madeira, destinado à maternidade, com três amplas enfermarias e demais dependências, e adquirido um pequeno sítio para produção de leite, a ser distribuído às crianças carentes. A disponibilidade orçamentária comportava tal empreendimento, mas não ia ao encontro da programação do Governo nem dos interesses daqueles que executariam a obra (MARTINS, 1989, p. 113).

Rubens Martins destaca que o diretor do Departamento Estadual da Criança, na época, "louvou a iniciativa" e teria afirmado que "o projeto sugerido seria mais útil à população"; contudo, justificou que "os governos preferem construir obras perenes que se constituam em marcos de suas administrações, a viabilizar projetos de duração efêmera

\footnotetext{
${ }^{4}$ Foi o primeiro prefeito de Francisco Beltrão, exercendo o mandato de 1953 a 1956. Desempenhou outras funções de destaque no município e foi sócio fundador da APMI.

${ }^{5}$ O Departamento Estadual da Criança - DECr, foi criado, no Estado do Paraná, em 13 de maio de 1947 pelo Decreto-Lei $n^{\circ}$ 615, regulamentado e aprovado pelo Governador Moisés Lupion, em 20 de junho do mesmo ano, através do Decreto 2.517, e tinha por finalidade coordenar as ações relativas à proteção à maternidade, à infância e à adolescência.

${ }^{6}$ Os Postos de Puericultura foram uma das frentes de ação do programa de governo do DECr, na década de 1950, no combate à mortalidade infantil, compondo um conjunto de ações de assistência ao binômio mãe-filho que incluía lactários, maternidades, creches, bancos de leite humano, postos volantes, hospitais de crianças e artesanatos (ALVES, 2015).
} 
como as simples construções de madeira". Porém, o pequeno prédio de alvenaria destinado ao Posto de Puericultura não se tratou de uma obra perene, "tombou anos depois [...] para dar lugar ao edifício do fórum" (MARTINS, 1989, p. 113). A partir de consulta às atas ${ }^{7}$ da APMI identificou-se que o prédio abrigou o posto até a década de 1970. Ata de 8 de fevereiro de 1970 registra: "Ficou resolvido, depois de debater, a mudança do Posto de Puericultura, pois o prédio onde funciona se encontra em precárias condições" (APMI, 8 de fevereiro de 1970, fl. 9)

O autor acentua que, durante o período em que esteve em Francisco Beltrão, os serviços do Posto de Puericultura (Figura 1) estiveram sob os cuidados da Dra. Diva Sanson Martins, sua esposa e primeira-dama, e oferecia atendimento gratuito, medicamentos, enxovais, vacinas, leite em pó e "orientação útil e carinhosa" às crianças, gestantes e puérperas.

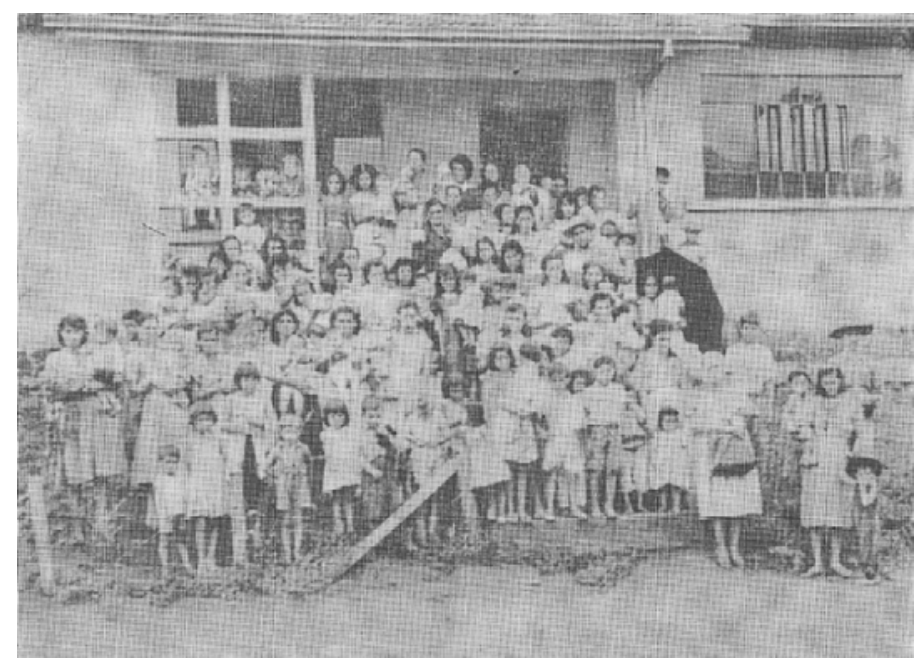

Figura 1 - Posto de Puericultura da Associação de Proteção à Maternidade e à Infância Dr. Haroldo Beltrão Posto de Puericultura. Clientela do Posto, década de 1950. Fonte: Martins (1986).

O atendimento prestado à população materno-infantil pela APMI não se restringia à distribuição dos recursos mencionados; juntamente, "momentos de lazer e de felicidade faziam parte da programação do Posto que, nos dias festivos - Dia da Pátria, Dia da Criança, Natal e outras datas comemorativas - promovia encontros" (MARTINS, 1986, p. 114). Esse enfoque prossegue acompanhando as atividades da APMI que efetuou, por algum tempo, a função de espaço cultural para encontro de mães e crianças. Assim, as datas festivas, já anunciadas por Martins, permaneceram por longo tempo sendo comemoradas em conjunto com mães e crianças. Na ocasião do Natal, conforme consta em ata, "para as mães de

\footnotetext{
${ }^{7}$ Foram consultadas as atas da APMI referentes ao período de 1968 até 2006.
} 
crianças pobres, do Clube [de mães] Papa João XVIII seria dado uma bola (para os meninos), uma boneca (para as meninas), e um bolo (para a mãe) " (ATA APMI, 18 de dezembro de 1971, fl. 18).

Martins (1986), em sua abordagem histórica, de caráter autobiográfico, sobre a constituição de Francisco Beltrão, sinaliza as condições da infância beltronense nessas primeiras décadas, sob o olhar médico. Acentua as situações recorrentes de desidratação e tantas outras doenças que assolavam a região, assim como as complicações de parto que presenciou pela falta de recursos e conhecimento da população. Foram essas suas motivações para a criação dessa instituição que demarcaria presença na cidade até os dias atuais, com a responsabilidade de representar (me arrisco a dizer) a mão do pioneiro que traz o progresso para a cidade. De sua narrativa tem destaque as expressões com que se refere às ações da APMI, que seriam a "boa causa" em prol dos "menos favorecidos da sorte". Desse modo, junto com a formação de Francisco Beltrão/PR, nasce a assistência à infância pobre do município, com a conotação marcante da época, como favor aos necessitados, que se propaga pelas décadas seguintes.

As atas da APMI, que abrangem as décadas de 1960 e 1970, apontam como atividades prestadas pela associação, no período, os clubes de mães, com o oferecimento de cursos de costura; o posto de puericultura; a assistência a meninos engraxates, através da doação de roupas e caixa de engraxate; assim como ações de assistência às famílias, através da doação de roupas, gêneros alimentícios, dentre outros. Destaca-se: "com a ajuda generosa [...] podia a diretoria fazer as primeiras compras para vestir, calçar quinze meninos engraxates, desta cidade, de preferência muito pobres, que não tivessem pai" (APMI, 8 de fevereiro de 1970, fl. 9). No mesmo ano, a diretoria reuniu-se com importantes representantes da sociedade, incluindo o prefeito, "a fim de entregar vinte uniformes, caixas e carteiras profissionais para meninos engraxates". Os meninos também recebem "calções, camisetas (sic) e chuteiras", a fim de formar um time de futebol (APMI, 9 de setembro de 1970, fl. 12). Isto denota as ações de preparação e incentivo ao trabalho em relação a este segmento da infância pobre para atuação em atividades de baixa qualificação, que pudessem reverterem-se em recursos para o sustento da família, em consonância com as políticas do menor vigentes à época (KUHLMANN JR, 2004; REDIN, 1985; DIDONET, 2016). 
Em ata de 22 de julho de 1972 (folha 22), consta que a diretoria delibera pela construção de uma sede própria da AMPI, a partir da arrecadação de recursos junto ao comércio local e senhoras da comunidade. Na referida ata, acentua-se que o local a ser construída esta sede deveria ser compatível com a "finalidade, que é dar assistência à saúde, às mães e às crianças pobres da cidade". A exemplo das ações de assistência prestadas por esta instituição a ata da APMI, de 27 de abril de 1970 (fl. 10), registra-se que, para o Clube de Mães Papa João XXIII "ficou combinada a compra de um fogareiro a gás (sic), panela e pratos. Neste clube deverá ser feita uma sopa bem nutritiva para as mães e suas crianças que vem em grande número". Os documentos explicitam o trabalho da APMI junto às famílias de menor renda.

A narrativa permite identificar a infância pobre como destinatária da APMI, que integrou em suas ações saúde, assistência e educação nos moldes da assistência à infância já consolidada no Brasil, voltada às crianças "carentes" e "desvalidas" (KUHLMANN JR, 2004; REDIN, 1985). Acerca disso, na história das políticas de assistência à infância é possível perceber que a sociedade e o Estado "foram sensíveis à criança e tomaram iniciativas para melhorar suas condições de vida e desenvolvimento", e assumiram que era seu dever cuidar das crianças. Contudo, até a promulgação da Constituição Federal de 1988 a perspectiva que predominou no campo das políticas à infância destinava-se a uma parcela da infância (DIDONET, 2016, p. 65). Nesse sentido, as políticas:

a. incidiam sobre uma parcela das crianças e um tipo de infância - a das crianças órfãs, pobres, abandonadas, "desvalidas", filhas de escravos, enjeitados (mesmo de famílias ricas), deficientes, delinquentes, "em situação irregular". Todas as demais crianças não constituíam assunto do Estado, mas da família [...].

b. a tônica da ação era a proteção nas situações desfavoráveis à vida da criança, o assistencialismo, a filantropia e, no caso do higienismo, o fortalecimento do povo por meio da saúde desde a infância. Não havia a noção de que aqueles serviços fossem uma resposta aos direitos da criança, apenas às suas necessidades [...] (DIDONET, 2016, p. 65).

Pautando suas ações por essa concepção de criança, a APMI também desempenhou importante papel na criação das primeiras creches municipais, o que será explicitado a seguir.

\section{Creches, mobral e cuidadoras domésticas compondo o cenário da educação da primeira infância em Francisco Beltrão}


Num contexto de desenvolvimento urbano em expansão, a primeira infância era assunto, até meados da década de 1980, de maneira mais direta da esfera familiar, contando com o apoio da APMI e Clubes de Mães. Nesse sentido, as famílias buscavam se organizar dentro das possibilidades que dispunham. Uma alternativa encontrada por algumas mães, que trabalhavam fora de casa, foi a realização desse cuidado, mediante pagamento, a uma mulher/mãe da comunidade. Noeli ${ }^{8}$, foi uma dessas cuidadoras domésticas que, durante a década de 1970, cuidou de crianças em sua casa. Na década seguinte, torna-se, em função dessa experiência, monitora de creche. Durante esse período, foram em torno de vinte crianças atendidas por ela, que chegou a cuidar ao mesmo tempo de, aproximadamente, oito crianças. Ao rememorar esse tempo, ela explica que as crianças eram cuidadas como se fossem seus filhos, recebiam os mesmos cuidados que suas filhas recebiam. Acentua que:

[...] algumas crianças eu peguei recém nascidas e elas saíram daqui com cinco, seis anos, até maiores, que praticamente a gente foi quem criou. Elas chamavam a gente de mãe, meu marido de pai. Não deixando de chamar a mãe deles também quando elas vinham. A gente tinha um carinho muito especial por eles e eles pela gente. Eles ficavam direto comigo, eles só saíam pra passear. Eles moravam aqui. [...] Sim, era como um internato, tinha épocas que tinham cinco, seis bercinhos na minha casa (NOELI, 2013).

Nesse contexto, é interessante destacar a atuação do Instituto Nossa Senhora da Glória, fundado pelas Irmãs Escolares de Nossa Senhora no mesmo ano que Francisco Beltrão tornou-se município, 1952. Esta instituição criou, ainda na década de 1950 (em 1954), o primeiro jardim de infância (BELLIATO, 2017; FRANCISCO BELTRÃO, 2007). Por tratar-se de uma instituição privada era destinada, de maneira geral, a um determinado grupo social, a "elite" beltronense que se constituía (FLAVIO, 2011).

No âmbito da educação pública, destaca-se a atuação do Movimento Brasileiro de Alfabetização $\left(\mathrm{Mobral}^{9}\right.$ ) no município, que proporcionou a expansão da reduzida oferta de

\footnotetext{
${ }^{8}$ Noeli W. Pumes foi uma das primeiras profissionais das creches municipais, atuou como monitora até a sua aposentadoria, no período de 1983 a 2009. Trabalhou com diferentes vínculos empregatícios e cargos - no período de 1983 até 1985 foi contratada como auxiliar de creche, após passou para monitora de creche, ambos com carteira assinada, e em 1992 assumiu o cargo na condição de servidora pública, após prestar concurso. Aposentou-se em 2009.

9 Programa do Governo Federal iniciado em 1971, cujo objetivo era a erradicação do analfabetismo no Brasil, sendo extinto em 1985, vinculado ao MEC. Na década de 1980 entrou no campo da educação pré-escolar. Arce (2008) afirma que o MOBRAL atuou pela expansão da educação infantil em todo o território brasileiro de maneira rápida e barata, carregando fortemente as marcas do voluntariado.
} 
turmas-de pré-escola a partir da década de 1980 . Milene ${ }^{10}$ assinala que praticamente não havia turmas de pré-escola nas escolas na época, e que "foi o Mobral que começou a fazer esse trabalho com o pré". A partir do projeto, que teria iniciado aproximadamente em 1979, ocorre a implantação do movimento no município, através do trabalho de pessoas leigas como ela: "eram pessoas leigas que queriam trabalhar na educação. Eu fiz o curso de uma semana em Dois Vizinhos, do Mobral, pra começar a trabalhar na educação infantil. Eu tinha 16 anos" (MILENE, 2013).

Zeneide $^{11}$, que iniciou como monitora de creche na década de 1980 , rememora seu início na educação infantil, que também ocorreu através do projeto do Mobral. Este, desenvolveu atividades em torno de quatro anos no município, onde turmas de pré-escola foram ofertadas em diversos espaços da comunidade considerados "ociosos". Ela pontua que "tinha nas igrejinhas, [...] nas escolas, nos pavilhões de igreja. Onde encontravam salinhas que dava pra formar turmas era feito". Milene confirma: "Eu trabalhei no Horto [bairro], eu trabalhei numa igrejinha, na igrejinha do Horto".

Zeneide narra como conheceu o projeto: "eu fiquei sabendo por que tinha uma prima que dava aula no [bairro] São Miguel, numa igrejinha, eu ia lá, e às vezes ajudava ela. Eu gostava. Ela era sozinha e tinha que fazer merenda e tal... e ela me convidou" Conforme Zeneide, quando foi contratada para atuar pelo Mobral, em torno de 1982, o projeto já era realizado na cidade aproximadamente a uns dois anos. Ela foi convidada pela coordenadora local do programa, que expressou o propósito do projeto: "a gente vai iniciar com vários 'prés' pra ajudar mais as pessoas carentes, as crianças". Conforme Zeneide, nesse período a equipe do Mobral passou a atuar nas escolas e, também, nas duas creches em funcionamento no período. Zeneide foi colocada, através do projeto, numa turma de préescola na Creche Nice Braga. Ela narra que trabalhava meio período com as crianças que permaneciam na creche em turno integral.

E em 1980, sob a responsabilidade da APMI e Departamento de Assistência Social, foi criada a primeira creche do município, junto ao recém inaugurado Centro Social Urbano,

\footnotetext{
${ }^{10}$ Milene Bernardon iniciou em 1994 e trabalha até os dias atuais na Prefeitura Municipal de Francisco Beltrão, tendo atuado nos cargos de Auxiliar Administrativo - Coordenação de Creche -, monitora de creche e professora de Educação Infantil. Atuou no Mobral entre 1979 e 1981.

${ }^{11}$ Zeneide Pazzeto iniciou em 1982 e trabalha até os dias atuais na Prefeitura Municipal de Francisco Beltrão, tendo atuado nos cargos de Auxiliar Administrativo - Coordenação de Creche -, monitora de creche e professora de Educação Infantil.
} 
para atender crianças de 0 a 6 anos (FRANCISCO BELTRÃO, 2007). Lourdes ${ }^{12}$, Primeira Dama e presidente da APMI no período da criação da primeira creche, explica que no início de sua gestão foram reestruturados e ampliados os Clubes de Mães e, a partir desse trabalho com as mães, a entrevistada rememora:

[...] a gente começou a ver a dificuldade das mães que precisavam trabalhar. Não tinham com quem deixar seus filhos, e nos próprios cursos que elas vinham, a gente tinha uma sala com bercinho, colchão no chão e tal, pra elas trazerem as crianças e poder participar (LOURDES, 2013).

Desse modo, a criação da primeira creche delineia-se em função dessa necessidade. Lourdes explica que logo que assumiu a frente da APMI foi à Superintendência Estadual da Legião Brasileira de Assistência - LBA ${ }^{13}$, em Curitiba, para estabelecer convênio a fim de dar continuidade ao trabalho com o Clube de Mães ${ }^{14}$. Na ocasião, Lourdes afirma ter tomado conhecimento dos outros projetos da LBA, e acentua que "conversando com elas [equipe da LBA] nós vimos todos os benefícios que a LBA poderia estar trazendo aqui pra Francisco Beltrão, e as creches eram um deles". Na ata da APMI (24 de junho de 1977) consta que, em audiência com o governador Jaime Canet Junior, seria solicitado a instalação de uma creche (juntamente com Cemic, guarda mirim, Parques Infantis e maquinas de costura).

A criação da primeira creche municipal somente foi efetivada em 1980, com recursos da LBA. A partir dos recursos disponibilizados por este órgão foram criadas e mantidas as primeiras creches, por ação da APMI e do setor de Assistência Social municipal. A LBA tinha, na época, um programa de creches de abrangência nacional, o projeto Casulo. 0 Casulo foi criado em 1977, tratava-se de um projeto que atuava através de convênios, repassando verbas para prefeituras ou entidades privadas com a finalidade de atender crianças provenientes da população de baixa renda. O projeto previa a instalação das

\footnotetext{
12 Lourdes V. Arruda foi presidente da APMI; nos períodos de 1977 a 1983 e 1993 a 1996, na condição de 1’a. Dama, também foi membro da diretoria em diversos outros períodos e assumiu como secretária da Assistência Social em 2001, estando à frente dessa secretaria, bem como da APMI, até 2012.

${ }^{13}$ A LBA foi criada em 1942, pela ação da primeira-dama Darcy Vargas, com a finalidade de prestar serviços de assistência social, tendo em vista proteger a maternidade e a infância com ênfase na família dos convocados para a II Guerra Mundial. A partir de 1946, volta-se exclusivamente à maternidade e à infância, constituindo-se em órgão de consulta do Estado brasileiro, e foi extinta em 1995. A instituição passa a efetuar suas ações através dos centros de proteção à criança e à mãe, as APMI, que passam a ser difundidos por todo Brasil, sendo considerada a primeira instituição de assistência social de âmbito nacional (KRAMER, 1987; CAMPOS, ROSEMBERG e FERREIRA, 1995).

${ }^{14}$ Estes Clubes na época e ainda hoje presentes no município tratam-se de associações de mulheres, estabelecidas por bairros, organizadas pela APMI, em que se realizavam cursos profissionalizantes para as mulheres que não possuíam fonte de renda.
} 
creches em equipamentos simples e pautava-se por uma concepção preventiva e compensatória de atendimento infantil (ROSEMBERG, 2006; CAMPOS, ROSEMBERG, FERREIRA, 1995)

A APMI foi responsável por coordenar e desenvolver ações relacionadas às creches, juntamente com o Departamento de Ação Social - DAS - que, mais tarde, viria a ser a Secretaria de Assistência Social - desde a criação da primeira creche em 1980 até a década de 2000, período em que as creches foram transferidas para a responsabilidade da Secretaria Municipal de Educação.

As condições de pobreza de parte significativa da população beltronense se sobressaem no final da década de 1970, quando começa a ser gestado o projeto de creches. Esse elemento é ratificado por Lourdes e é identificado como a motivação para o início das atividades com as creches:

[...] nós tínhamos uma pobreza muito grande, [...] ali no Entre Rios, [...], ali era chamado Vila Piolho; era horrível, aqui atrás da delegacia eram uns barracos um emendado no outro, lá no Padre Ulrico da mesma forma, aqueles barracos emendados um no outro, sabe, pessoas doentes! (LOURDES, 2013).

Lourdes assinala que "essas mães nos procuravam pra buscar comida, precisavam de tudo [...] a maioria não trabalhava [...] porque elas tinham os seus filhos e com quem elas iriam deixar os filhos pra poder buscar uma melhoria?". Conforme sua narrativa, foi a partir dessa percepção que sentiu a necessidade de criar as creches, "foi em função dessa demanda grande de mães desocupadas, não por vontade delas, mas pela situação".

Nesse contexto, em 1980 foi criada a primeira creche em Francisco Beltrão que foi implantada junto ao Centro Social Urbano - CSU Nice Braga, que havia iniciado recentemente seu funcionamento. O Centro Social Urbano foi um projeto de âmbito nacional que, através do Decreto no 75.922/1975, criou o Programa Nacional de Centros Sociais Urbanos, implantados em diversos municípios brasileiros no período entre 1975 e 1984, com a finalidade promover a integração social por meio do envolvimento da população em atividades comunitárias, nas áreas de educação e cultura, saúde e nutrição, desporto, trabalho, previdência e assistência social, recreação e lazer (BORBA, 1991)

No município, suas atividades principais foram o atendimento na área da saúde, a Guarda Mirim, cursos para mulheres, através do Clube de Mães e a creche (CMEI NICE 
BRAGA, 2008). A creche, atualmente denominada Centro Municipal de Educação Infantil Nice Braga ${ }^{15}$, dividia espaço com o atendimento a adolescentes e adultos (CMEI NICE BRAGA, 2008). A seguir, a Figura 2 e a Figura 3 apresentam fotografias da instituição na década de 1980.

A Figura Erro! Autoreferência de indicador não válida.2 retrata a sala do berçário e permite perceber que era uma sala pequena, mas que um planejamento para sua organização (pintura das paredes, cortinas, berços padronizados). Leonilde $\operatorname{Rios}^{16}$ ao rememorar a criação da primeira creche acentua: "se tu visse os bercinhos que nós montamos, com mosquiteiro, tudo coisa mais linda, tinha quatro berços, era dois de um lado e dois de outro". Já a Figura 3 retrata a turma de pré-escola e mostra que esta turma já não possuía as mesmas condições do berçário, era um espaço compartilhado com os adultos que realizavam curso de capacitação no CSU.

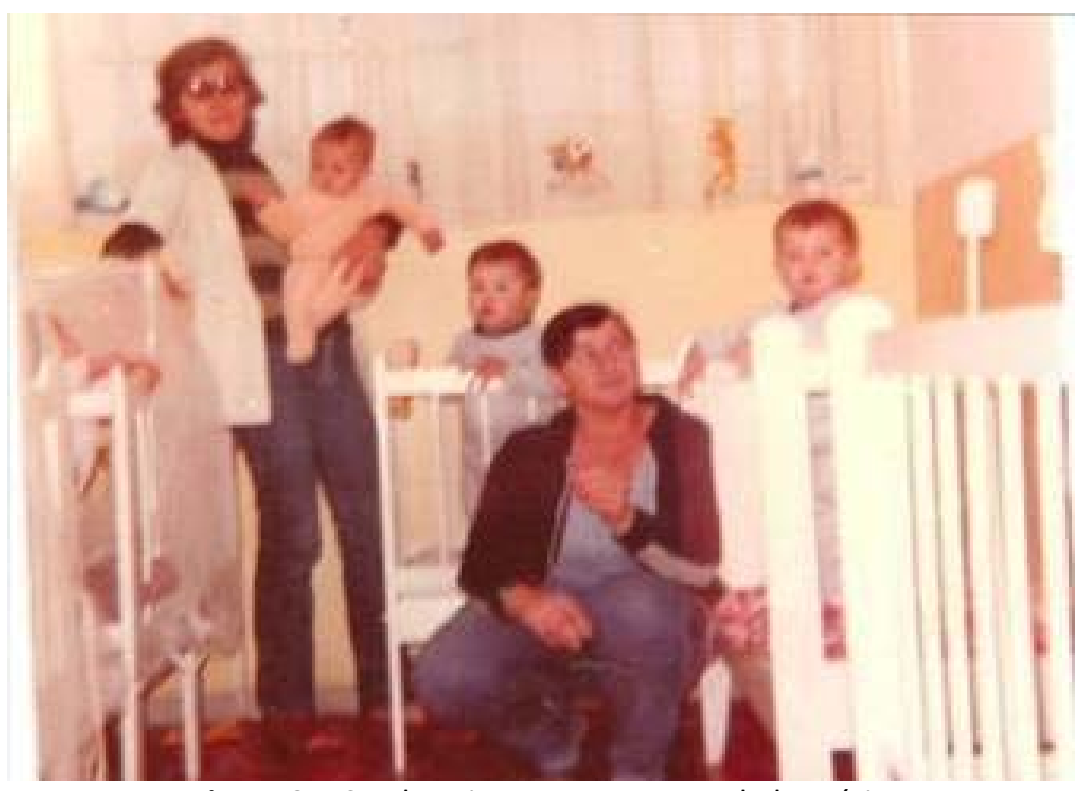

Figura 2 - Creche Nice Braga - Turma do berçário Monitora Laura Jung e Educadora Infantil Cleusa Strapazzon Fernandes, 1981. Fonte: Acervo pessoal Cleusa Strapazzon Fernandes.

\footnotetext{
${ }^{15}$ Criado e instalado em 1994 e regulamentado pelo Decreto Municipal no 451 de 15 de Setembro de 1995 (CMEI NICE BRAGA, 2008).

16 Leonilde Rios foi coordenadora pedagógica do CSU na época e, durante as gestões seguintes de Lourdes Arruda, foi coordenadora pedagógica da APMI.
} 


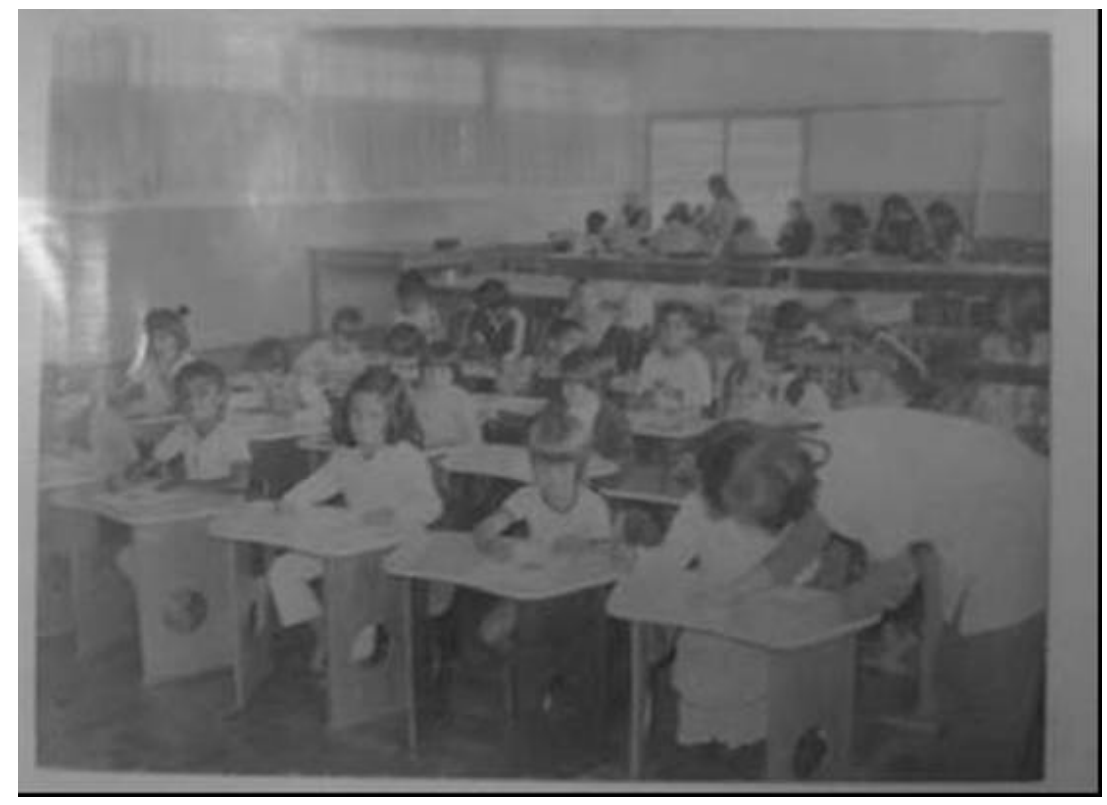

Figura 3 - Creche Nice Braga - Turma Pré-Escola Fonte: Relatório de atividades APMI, 1980-1981. S/I.

Lourdes ressalta que, antes de iniciar as atividades da creche, realizou uma visita a algumas creches do município de Maringá/PR, para conhecer sua estrutura e funcionamento. A entrevistada diz que iniciaram com 11 crianças e, no mês seguinte, já haviam 30 crianças. Sobre o início das atividades da creche Nice Braga, Leonilde explica que:

[...] fomos atendendo as famílias que realmente viviam em situação de risco, calamitosa mesmo. Então quem vinha pra creche eram as crianças que estavam passando por dificuldades de saúde, de nutrição, principalmente as desnutridas, eram as que a gente buscava na época. Nós tínhamos umas vilas assim muito precárias, e a gente foi em busca de atender essas famílias e trazer pra creche (LEONILDE, 2013).

Leonilde assinala que houve certa resistência das famílias, das entidades sociais e da Igreja Católica, no início das atividades. "No começo foi uma dificuldade, as mães pensavam que nós estávamos tirando as crianças delas, não era aquela busca para atender, e nós tínhamos que trabalhar com essas mães para que elas também se qualificassem, pra trabalhar fora". Lourdes explica que, posteriormente, à medida que a ideia começa circular pela cidade e as famílias passam a compreender que efetivamente não era uma política que tinha em vista "retirar as crianças do convívio familiar", ao contrário, se propunha a melhorar as condições das famílias, as creches começaram a ser uma demanda da própria comunidade.

O documento Programa Educação Infantil nas Creches - Normas técnicas, administrativas e pedagógicas, elaborado pela APMI, assinala, que o início do atendimento 
em creches, no município, teve em vista "propiciar condições favoráveis ao bom desenvolvimento da criança [...] e oferecer às mães, oportunidade de exercer um trabalho fora de casa para aumentar a renda familiar" (APMI, 1994, p. 05). Diante dessas necessidades da comunidade, outras instituições foram criadas posteriormente e apresentam um histórico de condições diferenciadas.

A primeira teria sido uma instituição piloto, tanto que, para o berçário, foi contratada uma auxiliar de enfermagem ${ }^{17}$, para o maternal uma professora, com formação no Curso Normal e, na turma de pré-escola atuou uma professora do projeto Mobral. Já as outras creches não tiveram as mesmas características: suas primeiras profissionais foram mulheres leigas com alguma experiência no cuidado de crianças.

É interessante refletir sobre o significado da resistência das mães em relação à creche. Esse elemento nos remete estabelecer relações mais amplas com o contexto da época, demarcado por políticas residualistas com enfoque no menor desassistido (NUNES; CORSINO, 2011). As representações acerca dessas políticas remetem à ideia do Estado que desempenha o papel de substituto da família no cuidado às crianças.

Faz-se necessário, por fim, considerar que as narrativas de memória impõem limites na medida em que recriam, à luz do presente, o retrato de um cenário. Portanto, as memórias são, pode-se dizer, possibilidades interpretativas de ler a realidade (AMADO, 1995; STEPHANOU; BASTOS, 2005).

[...] uma espécie de caleidoscópio composto por vivências, espaços e lugares, tempos, pessoas, sentimentos, percepções/sensações, objetos, sons e silêncios, aromas e sabores, texturas, formas. Movemos tudo isso incessantemente e a cada movimento do caleidoscópio a imagem é diversa, não se repete, há infinitas combinações, assim como, a cada presente ressignificamos nossa vida. Esse ressignificar consiste em nossos atos de lembrar e esquecer a partir das evocações do presente (STEPHANOU; BASTOS, 2005, p. 420).

Sendo assim, a memória não tem compromisso com a crítica, com a problematização, compõe-se de lembranças e esquecimentos, é vestígio. Trata-se de um indício que permite ao historiador produzir leituras do passado, "do vivido, do sentido, do experimentado pelos indivíduos" (STEPHANOU; BASTOS, 2005, p. 420). Nessa perspectiva, a

\footnotetext{
${ }^{17}$ Laura K. Jung atuava no hospital como auxiliar de enfermagem; porém, não possuía formação acadêmica para exercer a atividade.
} 
memória, por seu pertencimento, sacraliza o vivido pelo grupo social, enquanto que cabe à história, por tratar-se de operação intelectual, dessacralizar a memória, constituindo-se em representação do passado (FÉLIX, 1998).

O conjunto de documentos escritos, orais e de imagem que compuseram o conjunto de dados da pesquisa possibilitou visualizar elementos significativos do contexto investigado, propiciando identificar práticas e representações que compuseram o tempo e o lugar.

\section{Considerações finais}

Nesta escrita ficam evidenciadas práticas e representações relativas à infância que compuseram o cenário beltronense, as quais nos permitem vislumbrar o lugar ocupado pela infância na sociedade a partir de uma perspectiva histórica. Este trabalho visibiliza modos de viver a infância e educar as crianças que se cruzam e combinam compondo um desenho particular do contexto, onde o processo de institucionalização da infância é assinalado por um conjunto de representações que delimitam o que é ser criança e como educar. A pesquisa explicita que o cuidado à infância beltronense foi, desde o início da organização política do município, não somente assunto da esfera familiar, mas foi compartilhado com a sociedade e o Estado, a partir de uma concepção que tomava a criança por "objeto do cuidado, a destinatária silenciosa, a carente e precisada da atenção" (DIDONET, 2016, p. 65).

Por fim, é importante destacar, nesse processo, a contribuição da história cultural que, ao ampliar a noção do que é considerado documento, possibilitando colocar memórias e imagens na condição de documentos de pesquisa, oferece importantes recursos para a compreensão do tema, ampliando as perspectivas de análise. As memórias e as imagens possibilitam visualizar práticas de outros tempos, identificar códigos compartilhados, observar especificidades da vida cotidiana de pessoas e entidades que somente os documentos escritos não permitiriam. Foram os pontos de contato entre diferentes materiais que constituídos em documentos de pesquisa proporcionaram a escrita de uma história e a preservação de uma memória, tendo em vista que são poucos os documentos escritos que possibilitam conhecer a história das infâncias beltronenses.

Buscou-se reconstituir cenas em que se delinearam práticas particulares, próprias desse contexto, que, ao serem visibilizadas, permitem ampliar o conhecimento sobre a 
infância. A presente abordagem permite assinalar que "por trás das histórias desordenadas dos governos ou dos grandes acontecimentos, desenham-se histórias quase imóveis ao olhar, encontrando-se aí a história possível, ouvindo sujeitos que talvez nunca viessem a ser conhecidos (FISCHER, 2005, p. 260).

\section{REFERÊNCIAS BIBLIOGRÁFICAS}

ALVES, J. M. Assistência aos pobres em Londrina: 1940/1980. Londrina/PR: Eduel, 2015.

AMADO, J. O grande mentiroso: tradição, veracidade e imaginação em história oral. História, São Paulo, SP, n. 14, p. 125-136, 1995. Disponível em:

http://www2.fct.unesp.br/docentes/geo/necio_turra/PPGG\%20-

\%20PESQUISA\%20QUALI\%20PARA\%20GEOGRAFIA/AMADO\%20-\%200\%20grande\%20mentiroso.pdf Acesso em: 13 jan. 2018.

APMI. Associação de Proteção à Maternidade e a Infância. Programa Educação Infantil nas creches: Normas técnicas, administrativas e pedagógicas. APMI, 1994. . Livro Ata 1970. Ata APMI, 08 de fevereiro de 1970.

Livro Ata 1970. Ata APMI, 27 de abril de 1970.

. Livro Ata 1970. Ata APMI, 09 de setembro de 1970.

Livro Ata 1972. Ata APMI, 22 de julho de 1972.

Livro Ata 1977. Ata APMI, 24 de junho de 1977.

ARIÈS, P. História Social da Criança e da Família. Rio de Janeiro: Guanabara. 2ª ed., 1981.

BELLIATO, M. C. O Colégio Nossa Senhora da Glória e o processo de escolarização no município de Francisco Beltrão - PR (1951-1982). Dissertação (Mestrado). Universidade Estadual do Oeste do Paraná. Francisco Beltrão, 2017.

BORBA, S. V. A produção de equipamentos urbanos como alternativa de política social - o programa nacional de Centros Sociais Urbanos. Ensaios FEE. Porto Alegre, Vol 12, N 2, p. 403 - 421, 1991. Disponível em: <https://revistas.fee.tche.br/index.php/ensaios/article/view/1455> Acesso em: 13/06/2016.

BURKE, P. O que é História Cultural? Rio de Janeiro: Zahar, 2008.

CAMPOS, M. M.; ROSEMBERG, F.; FERREIRA, I. M. Creches e pré-escolas no Brasil. São Paulo: Cortez, 1995.

CENTRO MUNICIPAL DE EDUCAÇÃO INFANTIL NICE BRAGA. Proposta Pedagógica. Francisco Beltrão: SMECE, 2008.

CHARTIER, R. À beira da falésia: a história entre incertezas e inquietude. Porto Alegre: Ed. Universidade/UFRGS, 2002.

DEL PRIORE, M. (Org.). História das crianças no Brasil. 5ạ ed. São Paulo: Contexto, 2006.

DIDONET, V. Trajetória dos direitos da criança no brasil - de menor e desvalido a criança cidadã, sujeito de direitos. In: CÂMARA DOS DEPUTADOS. Cadernos de estudos e Debates 1: Avanços do Marco Legal da Primeira Infância. Brasília: Câmara dos Deputados, 2016.

FÉLIX, L. O. História e Memória: a problemática da pesquisa. Passo Fundo: EDIUPF, 1998.

FISCHER, B. T. D. Histórias de professores em Novo Hamburgo e São Leopoldo/RS (1930-2000): memórias e acervos. In: XIV ENDIPE - Encontro Nacional de Didática e Prática de Ensino. Porto Alegre: PUC/RS, Anais..., v. 1, 2008. 
Professoras: Histórias e discursos de um passado presente. Pelotas: Seiva Publicações, 2005.

FLÁVIO, L. C. Memória(s) e território: elementos para o entendimento da constituição de Francisco Beltrão-PR. Tese (Doutorado). Universidade Estadual Paulista "Júlio Mesquita Filho" Presidente Prudente, 2011.

FRANCISCO BELTRÃO. Plano Municipal de Educação. Francisco Beltrão: Prefeitura Municipal/Secretaria Municipal de Educação, Cultura e Esporte, 2007. . Caderno Francisco Beltrão. Prefeitura Municipal/SMECE, 2002.

GRAZZIOTIN; L. S.; ALMEIDA, D. B. Romagem do tempo e recantos da memória: reflexões metodológicas sobre história oral. São Leopoldo: Oikos, 2012.

HEYWOOD, C. Uma história da infância: da Idade Média à Época Contemporânea no Ocidente. Porto Alegre: Artmed, 2004.

KRAMER, S. A política do pré-escolar no Brasil: A arte do disfarce. São Paulo: Cortez, 1987.

KUHLMANN JR., M. Infância e Educação no Brasil - uma abordagem histórica. São Paulo: Saraiva, 2004.

LAZIER, H. Análise histórica da posse de terra no sudoeste paranaense. Francisco Beltrão: Grafit, 1997.

MARTINS, R. Entre jagunços e posseiros. Curitiba: Associação Marrecas do Bem Estar do Menor, 1986.

NUNES, M. F. R.; CORSINO, P. Políticas públicas universalistas e residualistas: os desafios da educação infantil. In: ROCHA, E. A. C.; KRAMER, S. Educação Infantil: enfoques em diálogo. São Paulo: Papirus, 2011.

ROSEMBERG, F. A LBA, o Projeto Casulo e a Doutrina de Segurança Nacional. In: FREITAS, M. F. História social da infância no Brasil. 6ạ Ed. São Paulo: Cortez, 2006.

PESAVENTO, S. J. História Cultural: caminhos de um desafio contemporâneo. In: PESAVENTO, S. J.; SANTOS, N. M. W.; ROSSINI, M. S. (orgs.). Narrativas, imagens e práticas sociais: percursos em história cultural. Porto Alegre, RS: Asterisco, 2008.

POLLAK, M. Memória, esquecimento, silêncio. Estudos históricos, vol. 2, n 3, p. 3-15, 1989.

REDIN, E. A representação da criança pré-escolar no Brasil - Pesquisa baseada em fatores explícitos e implícitos na legislação e na reflexão sobre a realidade da educação infantil em nosso meio. Tese (Doutorado). Universidade de São Paulo. São Paulo, 1985.

ROCHA, H. H. P.; GOUVÊA, M. C. S. Apresentação. Dossiê Infâncias na História. Educação em Revista. Belo Horizonte. v.26, n.01, p.187-194, abr. 2010. Disponível em: $<$ http://www.scielo.br/scielo.php?script=sci_arttext\&pid=S0102-

$46982010000100009 \&$ Ing=pt\&nrm=iso\&tlng=pt> Acesso em: 13 jan. 2018.

SARMENTO, M. J. A reinvenção do ofício de criança e de aluno. Atos de pesquisa em educação, v. 6, n. 3, p. 581-602, set./dez. 2011. Disponível em: <http://proxy.furb.br/ojs/index.php/atosdepesquisa/article/view/2819> Acesso em: 25 mar. 2014.

STEPHANOU, M. e BASTOS, M. H. C. História, memória e história da educação. In: STEPHANOU, M. e BASTOS, M. H. C. Histórias e memórias da educação no Brasil. Vol. III: Século XX. Petrópolis: Vozes, 2005. 